\title{
Development and validation of database indexes of asthma severity and control
}

\author{
Faranak Firoozi, Catherine Lemière, Marie-France Beauchesne, Amélie Forget, Lucie Blais
}

Thorax 2007;62:581-587. doi: 10.1136/thx.2006.061572

See end of article for authors' affiliations

Correspondence to:

Dr Lucie Blais, Université de

Montréal, Faculté de

pharmacie, CP 6128

Succursale Centre-ville,

Montreal, Québec, Canada

H3C 3J7; lucie.blais@

umontreal.ca

Received 1 March 2006

Accepted 18 December 2006

Published Online First

7 February 2007

\begin{abstract}
Background: The use of administrative databases to perform epidemiological studies in asthma has increased in recent years. The absence of clinical parameters to measure the level of asthma severity and control is a major limitation of database studies. A study was undertaken to develop and validate two database indexes to measure the control and severity of asthma.

Methods: Database indexes of asthma severity and control were derived from definitions in the Canadian Asthma Consensus Guidelines based on dispensed prescriptions and on medical services recorded in two large administrative databases from the Canadian province of Québec (Régie de l'Assurance Maladie du Québec (RAMQ) and MED-ECHO) over 12 months. The database indexes of asthma severity and control were validated against the pulmonary function test results of 71 patients with asthma randomly selected from two asthma clinics, and they were also applied to a cohort of patients with asthma followed up for 139283 person-years selected from the RAMQ and MED-ECHO databases between 1 January 1997 and 31 December 2004.

Results: According to the database indexes, $49.3 \%, 29.6 \%$ and $21.1 \%$ of patients recruited at the asthma clinics were found to have mild, moderate and severe asthma, respectively, while $53.5 \%$ were found to have controlled asthma. The mean predicted value of the forced expiratory volume in $1 \mathrm{~s}\left(\mathrm{FEV}_{1}\right)$ ranged from $89.8 \%$ for mild asthma to $61.5 \%$ for severe asthma $(p<0.001)$, whereas the range from controlled to uncontrolled asthma was $89.5 \%$ to $67.3 \%(p<0.001)$. The ratio of the $\mathrm{FEV}_{1}$ to the forced vital capacity $\left(\mathrm{FEV}_{1} /\right.$ FVC ratio) measured in 56 patients ranged from $75.8 \%$ for mild asthma to $61.8 \%$ for severe asthma $(p=0.030)$, whereas the range from controlled to uncontrolled asthma was $75.3 \%$ to $65.7 \%(p<0.001)$.

Conclusion: In the absence of clinical data, these database indexes could be used in epidemiological studies to assess the severity and control of asthma.
\end{abstract}

$\mathrm{T}$ he accurate classification of asthma severity and control is a significant challenge since they are conceptually related and there is an overlap in some of the criteria used in their assessment. The optimal control of asthma has been defined by the presence of minimal respiratory symptoms, no activity limitation, normal respiratory function and absence of the need for rescue bronchodilator. ${ }^{1-3}$ The current series of criteria used in assessing the control of asthma were established by the Global Initiative for Asthma (GINA) and the Canadian Asthma Consensus Guidelines, ${ }^{23}$ and include daytime and nocturnal symptoms, the occurrence of asthma exacerbations, the need for inhaled short-acting $\beta_{2}$ agonists (SABA), physical activity, absenteeism and forced expiratory volume in $1 \mathrm{~s}\left(\mathrm{FEV}_{1}\right)$ or peak expiratory flow (PEF) values.

Different methods are advocated by various guidelines to assess asthma severity. ${ }^{1-3}$ The GINA guidelines and the US National Asthma Education and Prevention Program consensus guidelines rely on evaluation of the inherent symptoms of the disease and the patient's lung function before instigating any treatment relative to the assessment of its severity. ${ }^{2}$ However, the Canadian Asthma Consensus Guidelines assess asthma severity once the treatment has been instigated and use a combination of factors, many of which overlap with measures of symptom control. These include pulmonary function tests, treatment required to obtain asthma control, history of hospital admissions and life-threatening asthma attacks. ${ }^{3}$

The use of administrative health databases to perform epidemiological studies in asthma has increased in recent years. ${ }^{4-6}$ The absence of clinical parameters to measure the level of asthma severity and control has always been considered one of the limitations of using administrative databases in this field of research. The development of indexes of asthma severity and of asthma control based on electronically available data is therefore desirable. Indeed, it is important to be able to measure asthma severity and control separately since, for example, in some studies it might be necessary to evaluate the control of asthma following a new treatment strategy, while in others it might be necessary to measure the level of severity of asthma before starting a new treatment.

Several validated multidimensional indexes of asthma control and severity have been developed for use in epidemiological and clinical studies..$^{7-12}$ These indexes are usually based on one or several factors that are considered clinically important in the assessment of asthma severity and control such as frequency, duration and intensity of symptoms and pulmonary function tests. However, to the best of our knowledge, none of these indexes relies solely on data usually recorded in administrative health databases.

The aim of this study was to develop and validate two database indexes, one to measure the control of asthma and the other to measure the severity of asthma in currently treated patients with asthma, using information related to dispensed asthma medications and medical services obtained from the administrative healthcare databases of the Canadian province of Québec.

Abbreviations: COPD, chronic obstructive pulmonary disease; $E D$, emergency department; ICS, inhaled corticosteroid; $\mathrm{FEV}_{1}$, forced expiratory volume in $1 \mathrm{~s}$; LABA, long-acting $\beta_{2}$ agonist; PEF, peak expiratory flow; SABA, short-acting $\beta_{2}$ agonist 
Table 1 Definition of the database indexes of asthma severity and control developed according to the Canadian Asthma Consensus Guidelines

\begin{tabular}{|c|c|c|c|c|}
\hline Asthma severity and control & ICS daily dose* $(\mu \mathrm{g})$ & Other controller therapy $\dagger$ & SABA doses per week‡ & $\begin{array}{l}\text { Marker of moderate to } \\
\text { severe exacerbations } \$\end{array}$ \\
\hline \multicolumn{5}{|l|}{ Mild } \\
\hline \multirow[t]{2}{*}{ Controlled } & $0-500$ & No & $0-3$ & No \\
\hline & $0-250$ & Yes & $0-3$ & No \\
\hline \multirow[t]{4}{*}{ Uncontrolled } & $0-250$ & Yes & $0-3$ & Yes \\
\hline & $0-500$ & No & $0-3$ & Yes \\
\hline & $0-250$ & Yes & $4-10$ & No \\
\hline & $0-500$ & No & $4-10$ & No \\
\hline \multicolumn{5}{|l|}{ Moderate } \\
\hline \multirow[t]{3}{*}{ Controlled } & $251-500$ & Yes & $0-10$ & No \\
\hline & $501-1000$ & Yes/no & $0-10$ & No \\
\hline & $>1000$ & Yes/no & $0-3$ & No \\
\hline \multirow[t]{8}{*}{ Uncontrolled } & $0-250$ & Yes & $4-10$ & Yes \\
\hline & $0-500$ & No & $4-10$ & Yes \\
\hline & $0-250$ & Yes & $>10$ & No \\
\hline & $0-500$ & No & $>10$ & No \\
\hline & $251-500$ & Yes & $>10$ & No \\
\hline & $251-500$ & Yes & $0-10$ & Yes \\
\hline & $501-1000$ & Yes/no & $>10$ & No \\
\hline & $501-1000$ & Yes/no & $0-10$ & Yes \\
\hline \multicolumn{5}{|l|}{ Severe } \\
\hline \multirow{4}{*}{$\begin{array}{l}\text { Controlled } \\
\text { Uncontrolled }\end{array}$} & $>1000$ & Yes/no & $4-10$ & No \\
\hline & $0-1000$ & Yes/no & $>10$ & Yes \\
\hline & $>1000$ & Yes/no & $0-10$ & Yes \\
\hline & $>1000$ & Yes/no & $>10$ & Yes/no \\
\hline
\end{tabular}

ICS, inhaled corticosteroid; SABA, short-acting $\beta_{2}$ agonist.

*Daily dose of ICS in beclomethasone-chlorofluorocarbon equivalent over a 12 month period.

†Other controller therapy: at least six prescriptions of long-acting $\beta_{2}$ agonist, theophylline or leucotriene receptor antagonists dispensed over a 12 month period. †Average number of inhaled short-acting $\beta_{2}$ agonist doses per week calculated over a 12 month period.

$\S$ An emergency department visit for asthma, a hospital admission for asthma or a filled prescription of an oral corticosteroid over a 12 month period.

\section{METHODS}

\section{Source of data}

Our database indexes of asthma severity and control are based on variables recorded in two administrative databases of the Province of Québec, Canada: Régie de l'Assurance-Maladie du Québec (RAMQ) and MED-ECHO. The RAMQ database provides information on medical services dispensed to all residents of Québec and on prescribed medications provided to residents covered by the RAMQ's Prescription Drug Insurance Plan. Approximately $43 \%$ of the population of Québec is covered by the RAMQ's Prescription Drug Insurance Plan which mainly includes older people, social aid recipients since 1980 and about 1.7 million new adherents since 1997, mostly workers and their families who, in socioeconomic terms, represent the average population. ${ }^{13}$ The RAMQ's Prescription Drug Insurance Plan database provides information on dispensed medications (date of filling, name, dose, quantity, dosage form and duration of the prescription) while the RAMQ's Medical Services database provides information on medical services dispensed in a clinic, an emergency department (ED) or a hospital (date and diagnosis coded with ICD-9). The RAMQ's databases also provide sociodemographic data such as age, sex, social aid status and, where relevant, date of death. Data recorded in the RAMQ's Prescription Drug Insurance database and asthma diagnoses recorded in the RAMQ's Medical Services database have been formally evaluated and deemed valid. ${ }^{14}{ }^{15}$

The MED-ECHO database is a provincial database which records data on acute care hospital admissions and covers all residents of Québec. For each hospital admission we obtained data on the primary and up to 15 secondary discharge diagnoses, date of admission, duration of hospital stay and treatments received while in hospital. ${ }^{15}$

\section{Description of database indexes of asthma severity and control}

The database indexes of asthma severity and control that we developed are based on the criteria detailed in the Canadian
Asthma Consensus Guidelines for assessment of the severity and control of patients with asthma who are already taking antiasthma medications. ${ }^{3}$ Three levels of asthma severity and two levels of asthma control were defined over a 12 month period based on the following: average daily dose of inhaled corticosteroid (ICS) in beclomethasone-chlorofluorocarbon equivalent; the use of additional controller therapies defined as at least six filled prescriptions of inhaled long-acting $\beta_{2}$ agonists (LABA), theophylline or leucotriene receptor antagonists within a 12 month period; the average number of doses of SABA per week; and the presence of markers of moderate to severe asthma exacerbations (a filled prescription for oral corticosteroids, an ED visit for asthma, or a hospital admission for asthma). ${ }^{16}$

Details of the two database indexes are presented in table 1. Briefly, the mild asthma category corresponds to ICS doses of 0$500 \mu \mathrm{g} /$ day for patients not receiving additional controller therapy and ICS doses of $0-250 \mu \mathrm{g} /$ day for patients receiving additional controller therapy. Moreover, in order to be classified in this mild category, a patient must not have had a marker of a moderate to severe asthma exacerbation nor have used more than an average of three doses of SABA per week during the 12 month period under study. The moderate asthma category corresponds to ICS doses of $>500 \mu \mathrm{g} /$ day for patients not receiving additional controller therapy or doses of $>250 \mu \mathrm{g} /$ day for those receiving additional controller therapy, except for patients with a high use of SABA and moderate to severe asthma exacerbations. Severe asthma is mainly characterised by ICS doses of $>1000 \mu \mathrm{g} /$ day, except for patients with both markers of uncontrolled asthma; for example, patients who are taking more than 10 doses of SABA per week and a marker for a moderate to severe asthma exacerbation.

Patients were considered as controlled if they had no marker for moderate to severe asthma exacerbations and were taking no more than 3 doses of SABA per week for mild asthma and 10 doses of SABA per week for moderate and severe asthma.

Using data from the RAMQ's databases, an algorithm was developed to calculate the mean daily dose of ICS and the mean 
weekly dose of SABA on the basis of prescription renewals, quantity of medication dispensed, duration of the prescription and time intervals between renewals. ${ }^{17}{ }^{18}$ In order to calculate the equivalence of the mean daily dose of ICS into beclomethasone-chlorofluorocarbon, we used the equivalency table published in the Canadian Asthma Consensus Guidelines. ${ }^{3}$ The pharmacist established the equivalencies for SABA; for example, one dose of SABA was equivalent to two inhalations of salbutamol from a metered dose inhaler (100 $\mu \mathrm{g} /$ inhalation $).{ }^{19}$

\section{Validation of database indexes of asthma severity and control}

In order to validate the database indexes of asthma severity and control, we applied them to the administrative database information available for a sample of patients with asthma recruited in two different asthma clinics. We then compared the actual mean pulmonary function test values for these patients across the classification categories to determine if pulmonary function corresponded with our indexes of severity and control. All the patients had a confirmed diagnosis of asthma with no diagnosis of chronic obstructive pulmonary disease (COPD). Fifty-six patients with asthma were recruited from the Montreal Chest Institute between May 2001 and February 2002. The most recent measures of $\mathrm{FEV}_{1}$ (predicted value) and $\mathrm{FEV}_{1} / \mathrm{FVC}$ were retrieved from their medical charts. Fifteen patients with asthma were recruited from the asthma clinic of the Hôpital du Sacré-Coeur de Montréal (HSCM) between January and March 2003 and their most recent $\mathrm{FEV}_{1}$ value was obtained from the medical chart. However, the $\mathrm{FEV}_{1}$ / FVC values were unavailable for this set of patients.

Information concerning the use of prescribed medications, history of hospital admissions and ED visits for asthma was obtained from the RAMQ and MED-ECHO databases for all patients. The data obtained from the RAMQ and MED-ECHO provided us with the necessary information to classify the severity and control for each patient using our database indexes.

\section{Application of database indexes of asthma severity and control}

Our database indexes of asthma severity and control were applied in a cohort of patients with asthma from Québec in order to obtain the distribution of asthma severity and control as classified by our indexes at a population level. The Québec cohort comprised 139283 person-years of follow-up of patients with asthma aged 14-44 years selected from RAMQ and MED-ECHO databases between 1 January 1997 and 31 December 2004. In order to be included in the cohort, patients had to have been diagnosed with asthma at least once between 1 January 1997 and 31 December 2004. Furthermore, their medications must have been covered by the RAMQ Prescription Drug Insurance Plan for at least 1 year before and 1 year after the index date (defined as 1 January after being diagnosed with asthma). Based on the aforementioned conditions, all the non-overlapping 1 year periods that fulfilled our criteria were identified. A patient could therefore contribute more than one episode of 1 year of follow-up into the cohort. The level of asthma severity and control was evaluated for each 1 year period included in the cohort using our database indexes. Data on dispensed medications, medical services and sociodemographic data were provided by the RAMQ while data relating to hospital admissions were supplied by MED-ECHO for all patients included in the cohort.

\section{Comparison of distribution of asthma severity levels across different study populations and severity indexes} For validation purposes, the distribution of the severity levels found in the Québec cohort using our database index of severity was compared with the distribution of the severity levels found in different populations worldwide using other severity indexes. The first severity index used for comparison was based on the GINA classification of symptoms and $\mathrm{FEV}_{1}$ which was applied in a sample of 4362 patients with asthma (51\% women) aged 16-45 years examined by clinical specialists in private practice throughout France between 3 and 28 May 1993. ${ }^{20}$ The second severity index used for comparison was also based on the measure of asthma severity reported in the GINA guidelines (frequency of symptoms) and was used in a sample of 2509 patients with asthma identified in the Asthma Insights and Reality (AIR) survey conducted in the USA in 1998. ${ }^{21}$ The third severity index with which our index was compared was based on patient's reported daily medication usage and was used in a sample of 1279 patients with asthma who had completed a telephone questionnaire and had filled inhaler prescriptions in community pharmacies in Ontario, Canada. ${ }^{7}$

\section{Statistical analysis}

The differences in mean $\mathrm{FEV}_{1}$ (percent predicted value) were compared between the levels of asthma severity and control within the sample of patients recruited at the asthma clinics. We also performed the same analysis stratified by age $(\leqslant 45$ and $>45$ years). A cut-off point of 45 years was used for this stratified analysis because the diagnosis of asthma is unlikely to be confused with a diagnosis of COPD in patients aged $<45$ years. Moreover, 45 years was the median age of the patient sample from the clinics, and patients $<45$ years of age would be more easily comparable to the patients in the Québec cohort. The comparison of the $\mathrm{FEV}_{1} / \mathrm{FVC}$ ratio between levels of asthma severity and control was only completed for patients recruited at the Montreal Chest Institute. Using the Student's $t$ test for independent samples, two-tailed pairwise comparisons were performed and $p$ values of $<0.05$ were considered significant. No adjustment for multiple testing was performed.

Table 2 Characteristics of study population over a 12 month period

\begin{tabular}{|c|c|c|}
\hline & $\begin{array}{l}\text { Patients selected } \\
\text { from asthma clinics } \\
\text { ( } n=71)\end{array}$ & $\begin{array}{l}\text { Quebec cohort of } \\
\text { asthmatic patients* } \\
\text { ( } n=139283 \\
\text { person-years) }\end{array}$ \\
\hline Mean (SD) age (years) & $49.0(17.8)$ & $30.3(8.7)$ \\
\hline Women (\%) & 62.9 & 62.2 \\
\hline \multicolumn{3}{|l|}{ ICS use, $\mu \mathrm{g}$ per day (\%)† } \\
\hline 0 & 28.2 & 37.0 \\
\hline $1-250$ & 15.5 & 34.3 \\
\hline $251-500$ & 18.3 & 11.9 \\
\hline $501-1000$ & 18.3 & 10.9 \\
\hline$>1000$ & 19.7 & 5.9 \\
\hline \multicolumn{3}{|l|}{$\begin{array}{l}\text { SABA, number of doses per } \\
\text { week }(\%) \ddagger\end{array}$} \\
\hline $0-3$ & 57.7 & 53.6 \\
\hline $4-10$ & 15.5 & 22.4 \\
\hline$>10$ & 26.8 & 24.0 \\
\hline LABA use (\%) & 54.9 & 23.4 \\
\hline Theophylline use (\%) & 9.9 & 2.3 \\
\hline $\begin{array}{l}\text { Leucotriene receptor } \\
\text { antagonist use (\%) }\end{array}$ & 21.1 & 7.7 \\
\hline Oral corticosteroid use (\%) & 31.0 & 16.5 \\
\hline Respiratory physician visit (\%) & 98.6 & 12.3 \\
\hline ED care for asthma (\%) & 11.3 & 18.1 \\
\hline Hospital care for asthma (\%) & 4.2 & 6.2 \\
\hline \multicolumn{3}{|c|}{$\begin{array}{l}\text { ICS, inhaled corticosteroid; SABA, short-acting } \beta_{2} \text { agonist; LABA, long- } \\
\text { acting } \beta_{2} \text { agonist; ED, emergency department. } \\
\text { *On average, patients contributed } 2.1 \text { episodes of } 1 \text { year into the cohort. } \\
\text { The cohort comprises patients with asthma selected from } 1 \text { January } 1997 \text { to } \\
31 \text { December } 2004 \text {. } \\
\text { †ICS daily dose in beclomethasone-chlorofluorocarbon equivalent over a } \\
12 \text { month period. } \\
\ddagger \text { Average number of inhaled short-acting } \beta_{2} \text { agonist doses per week } \\
\text { calculated over a } 12 \text { month period. }\end{array}$} \\
\hline
\end{tabular}


The distribution of the levels of asthma severity and control using our database indexes was estimated among the Québec cohort of patients with asthma. All statistical analyses were performed using SAS Version 8.02.

\section{Ethical considerations}

The link between the data obtained from the RAMQ database, the MED-ECHO database and the medical chart was made with a unique patient's identifier (patient health number) which is included in each database and medical chart. This link was approved by the Commission d'accès à l'information du Québec. This research project was approved by the ethics board of the Hôpital du Sacré-Cour de Montréal and the Montreal Chest Institute.

\section{RESULTS}

\section{Characteristics of study population}

The characteristics of the patients from the asthma clinics and the Québec cohort are shown in table 2. The mean age of the 139283 person-years of patients with asthma in the Québec cohort was lower than that for those from the asthma clinics (30.3 vs 49.0 years). Patients from the asthma clinics used more ICS than those in the Québec cohort (71.8\% vs 63.0\%). The use of more than 10 doses of SABA per week was higher in patients from the asthma clinics than in those in the Québec cohort $(26.8 \%$ vs $24.0 \%)$. In the sample of patients from the asthma clinics, $11.3 \%$ had at least one ED visit and $4.2 \%$ had at least one hospital admission for asthma over a 12 month period compared with $18.1 \%$ and $6.2 \%$, respectively, for patients in the Québec cohort.

\section{Application of database index of asthma severity and control}

The distribution of the levels of asthma severity and control based on our database indexes for the sample of 71 patients from the asthma clinics and the Québec cohort is shown in table 3. Among patients from the asthma clinics, 35 (49.3\%), 21 $(29.6 \%)$ and $15(21.1 \%)$ had mild, moderate and severe asthma, respectively. Overall, in the asthma clinic sample, $46.5 \%$ of patients were classified as having poorly controlled asthma; of those we classified as mild, moderate or severe, $20.0 \%, 57.1 \%$ and $93.3 \%$, respectively, had poorly controlled asthma by our criteria. When this sample was stratified by age, younger patients were found to be more likely to have mild asthma and controlled asthma than older patients. In the Québec cohort $63.4 \%, 22.6 \%$ and $14.0 \%$, respectively, had mild, moderate and severe asthma and $54.5 \%$ had uncontrolled asthma.

\section{Validation of database indexes of asthma severity and control}

The results of the analyses performed to validate our database indexes against pulmonary function measures are shown in table 4. For the index of severity, among the 71 patients from the asthma clinics, the mean predicted value of $\mathrm{FEV}_{1}$ was found to be $89.8 \%$ for mild asthma, $74.1 \%$ for moderate asthma and $61.5 \%$ for severe asthma. All pairwise comparisons of $\mathrm{FEV}_{1}$ between the three levels of asthma severity were found to be statistically significant $(\mathrm{p}=0.007$ for moderate vs mild asthma, $\mathrm{p}<0.001$ for severe vs mild asthma and $\mathrm{p}=0.033$ for severe vs moderate asthma). In the sample of 56 patients from the Montreal Chest Institute, the $\mathrm{FEV}_{1} / \mathrm{FVC}$ ratio ranged from $75.8 \%$ for mild asthma to $61.8 \%$ for severe asthma. Pairwise comparisons of the ratio were found to be statistically significant for mild versus moderate asthma $(p=0.006)$ and for mild versus severe asthma $(p=0.030)$, but the observed difference between moderate and severe asthma was not found to be statistically significant $(\mathrm{p}=0.205)$.

For the index of control, patients classified as well controlled had a mean $\mathrm{FEV}_{1}$ of $89.5 \%$ and $\mathrm{FEV}_{1} / \mathrm{FVC}$ ratio of $75.3 \%$, and those classified as poorly controlled had a mean $\mathrm{FEV}_{1}$ of $67.3 \%$ and a $\mathrm{FEV}_{1} / \mathrm{FVC}$ ratio of $65.7 \%$ using different subsets of clinic patients for the $\mathrm{FEV}_{1}$ and $\mathrm{FEV}_{1} / \mathrm{FVC}$ comparisons, as described in the Methods section. Differences between controlled and uncontrolled patients were found to be statistically significant $\left(p<0.001\right.$ for differences in $\mathrm{FEV}_{1}$ and for differences in $\mathrm{FEV}_{1} /$ FVC ratio).

The results of the analysis comparing $\mathrm{FEV}_{1}$ across the different levels of asthma severity and control stratified by age ( $\leqslant 45$ and $>45$ years) are shown in table 5 . Statistically significant differences were observed for all pairwise comparisons between severity levels except for the comparison of moderate and severe asthma in younger patients and the comparison of mild and moderate asthma in older patients. Differences in $\mathrm{FEV}_{1}$ between controlled and uncontrolled patients were statistically significant in both subgroups.

\section{Comparison of distribution of asthma severity among different populations}

The comparison of the distribution of asthma severity in the Québec cohort assessed against our database index and the distribution of asthma severity in other populations worldwide assessed against other severity indexes is presented in table 6 . In the Québec cohort the distribution of severity levels was 63\%, $23 \%$ and $14 \%$ for mild, moderate and severe asthma, respectively. This distribution was similar to those of two of the three study populations: $59-66 \%$ for mild asthma, around $22 \%$ for moderate asthma and $13-19 \%$ for severe asthma.

Table 3 Distribution of levels of asthma severity and control

\begin{tabular}{|c|c|c|c|c|}
\hline & \multicolumn{3}{|c|}{ Patients from asthma clinics } & \multirow[b]{2}{*}{$\begin{array}{l}\text { Quebec cohort of } \\
\text { patients with asthma } \\
\text { ( } n=139283 \text { person-years) }\end{array}$} \\
\hline & $\begin{array}{l}\text { All patients } \\
(n=71)\end{array}$ & $\begin{array}{l}\text { Patients } \\
\leqslant 45 \text { years } \\
(n=34)\end{array}$ & $\begin{array}{l}\text { Patients } \\
\begin{array}{l}>45 \text { years } \\
(n=37)\end{array}\end{array}$ & \\
\hline Mild & $35(49.3)$ & $20(58.8)$ & $15(40.5)$ & $88250(63.4)$ \\
\hline Controlled & $28(80.0)$ & $17(85.0)$ & $11(73.3)$ & $57529(65.2)$ \\
\hline Uncontrolled & $7(20.0)$ & $3(15.0)$ & $4(26.7)$ & $30721(34.8)$ \\
\hline Moderate & $21(29.6)$ & $9(26.5)$ & $12(32.4)$ & $31552(22.6)$ \\
\hline Controlled & $9(42.9)$ & $4(44.4)$ & $5(41.7)$ & $5488(17.4)$ \\
\hline Uncontrolled & $12(57.1)$ & $5(55.6)$ & $7(58.3)$ & $26064(82.6)$ \\
\hline Severe & $15(21.1)$ & $5(14.7)$ & $10(27.0)$ & $19481(14.0)$ \\
\hline Controlled & $1(6.7)$ & $0(0.0)$ & $1(10.0)$ & 377 (1.9) \\
\hline Uncontrolled & $14(93.3)$ & $5(100.0)$ & $9(90.0)$ & $19104(98.1)$ \\
\hline Controlled & 38 (53.5) & $21(61.8)$ & $17(45.9)$ & $63394(45.5)$ \\
\hline Uncontrolled & $33(46.5)$ & $13(38.2)$ & $20(54.1)$ & 75889 (54.5) \\
\hline
\end{tabular}


Table 4 Comparison of database indexes of asthma severity and control against lung function measures

\begin{tabular}{|c|c|c|c|c|}
\hline & Variable & $\mathbf{N}$ & Mean & p Value \\
\hline \multicolumn{5}{|c|}{$\begin{array}{l}\text { Asthma severity } \\
(\mathrm{N}=71)\end{array}$} \\
\hline Mild & $\mathrm{FEV}_{1}$ predicted $\%$ & 35 & 89.8 & \\
\hline Moderate & $\mathrm{FEV}_{1}$ predicted \% & 21 & 74.1 & $0.007^{*}$ \\
\hline Severe & $\mathrm{FEV}_{1}$ predicted \% & 15 & 61.5 & $\begin{array}{r}<0.001 \dagger \\
0.033 \ddagger\end{array}$ \\
\hline \multicolumn{5}{|l|}{$N=56$} \\
\hline Mild & $\mathrm{FEV}_{1} / \mathrm{FVC}$ & 30 & 75.8 & \\
\hline Moderate & $\mathrm{FEV}_{1} / \mathrm{FVC}$ & 18 & 68.1 & $0.006^{*}$ \\
\hline Severe & $\mathrm{FEV}_{1} / \mathrm{FVC}$ & 8 & 61.8 & $\begin{array}{l}0.030 \dagger \\
0.205 \ddagger\end{array}$ \\
\hline \multicolumn{5}{|c|}{$\begin{array}{l}\text { Asthma control } \\
(\mathrm{N}=71)\end{array}$} \\
\hline Controlled & $\mathrm{FEV}_{1}$ predicted $\%$ & 38 & 89.5 & \\
\hline $\begin{array}{l}\text { Uncontrolled } \\
N=56\end{array}$ & $\mathrm{FEV}_{1}$ predicted $\%$ & 33 & 67.3 & $<0.001$ \\
\hline Controlled & $\mathrm{FEV}_{1} / \mathrm{FVC}$ & 33 & 75.3 & \\
\hline Uncontrolled & $\mathrm{FEV}_{1} / \mathrm{FVC}$ & 23 & 65.7 & 0.001 \\
\hline
\end{tabular}

$\mathrm{FEV}_{1}$, forced expiratory volume in $1 \mathrm{~s}$; FVC, forced vital capacity.

*Moderate vs mild asthma.

†Severe vs mild asthma.

†Severe vs moderate asthma.

However, the Ontario population had a different distribution of severity with $28 \%$ for mild asthma, $49 \%$ for moderate asthma and $23 \%$ for severe asthma.

\section{DISCUSSION}

We have shown that our database indexes of asthma severity and control correlate well with lung function measures such as $\mathrm{FEV}_{1}$ and the $\mathrm{FEV}_{1} / \mathrm{FVC}$ ratio, which are reliable indices reflecting asthma severity and control. ${ }^{13}$ Moreover, the application of our database severity index to a populationbased cohort of patients with asthma led to a distribution of asthma severity similar to that found with other severity indexes applied in two of the three comparison samples.

The need to adjust for the level of asthma severity and control to minimise confounding is encountered in most epidemiological studies of asthma. However, these disease characteristics are not always easy to measure because of the lack of clinical data, especially in studies performed with administrative databases. To the best of our knowledge, our indexes of asthma severity and control are the first of this kind to be entirely based on data available from health administrative databases, and it will be possible to use them in future epidemiological studies in asthma.

Differences in the distribution of asthma severity and control found in the populations we studied are worthy of comment. Patients followed in asthma clinics of tertiary healthcare centres are more likely to have moderate or severe asthma and are more properly controlled because they benefit from follow-up by respiratory specialists. Our results reflect this, since the percentage of controlled patients in each level of severity was greater among patients from the asthma clinics than those from the Québec cohort. Moreover, we found that

Table 5 Age-stratified comparison of database indexes of asthma severity and control and $\mathrm{FEV}_{1}$ measures

\begin{tabular}{|c|c|c|c|c|}
\hline & Variable & $\mathbf{N}$ & Mean & p Value \\
\hline \multicolumn{5}{|c|}{$\begin{array}{l}\text { Asthma severity } \\
\leqslant 45 \text { years }(\mathrm{N}=34)\end{array}$} \\
\hline Mild & $\mathrm{FEV}_{1}$ predicted $\%$ & 20 & 95.2 & \\
\hline Moderate & $\mathrm{FEV}_{1}$ predicted $\%$ & 9 & 68.7 & $0.002^{*}$ \\
\hline Severe & $\mathrm{FEV}_{1}$ predicted $\%$ & 5 & 61.1 & $\begin{array}{l}0.002 \dagger \\
0.519 \ddagger\end{array}$ \\
\hline \multicolumn{5}{|c|}{$>45$ years $(\mathrm{N}=37)$} \\
\hline Mild & $\mathrm{FEV}_{1}$ predicted $\%$ & 15 & 82.6 & \\
\hline Moderate & $\mathrm{FEV}_{1}$ predicted $\%$ & 12 & 78.1 & $0.552^{*}$ \\
\hline \multirow[t]{2}{*}{ Severe } & $\mathrm{FEV}_{1}$ predicted $\%$ & 10 & 61.6 & $0.026+$ \\
\hline & & & & $0.015 \ddagger$ \\
\hline \multicolumn{5}{|l|}{ Asthma control } \\
\hline \multicolumn{5}{|c|}{$\leqslant 45$ years $(N=34)$} \\
\hline Controlled & $\mathrm{FEV}_{1}$ predicted $\%$ & 21 & 92.0 & \\
\hline Uncontrolled & $\mathrm{FEV}$, predicted $\%$ & 13 & 68.9 & 0.004 \\
\hline \multicolumn{5}{|c|}{$>45$ years $(\mathrm{N}=37)$} \\
\hline Controlled & $\mathrm{FEV}_{1}$ predicted $\%$ & 17 & 86.4 & \\
\hline Uncontrolled & $\mathrm{FEV}_{1}$ predicted $\%$ & 20 & 66.2 & 0.004 \\
\hline
\end{tabular}

$\mathrm{FEV}_{1}$, forced expiratory volume in $1 \mathrm{~s}$.

*Moderate vs mild asthma.

†Severe vs mild asthma.

†Severe vs moderate asthma. 
Table 6 Comparison of the distribution of asthma severity (\%) based on different indexes applied to different populations

\begin{tabular}{|c|c|c|c|c|}
\hline & $\begin{array}{l}\text { Cohort of asthmatic patients, } \\
\text { Quebec, Canada* } \\
\text { ( } n=139283 \text { person-years) }\end{array}$ & $\begin{array}{l}\text { Cohort of asthmatic patients, } \\
\text { France } e^{20} t \\
(n=4333)\end{array}$ & $\begin{array}{l}\text { AIR America survey, } \\
\text { USA }^{21} \ddagger \\
(\mathbf{n}=2509)\end{array}$ & $\begin{array}{l}\text { Cohort of asthmatic patients, } \\
\text { Ontario, Canada } \S \\
\text { ( } n=1279)\end{array}$ \\
\hline Mild asthma & 63 & 66 & 59 & 28 \\
\hline Moderate asthma & 23 & 21 & 22 & 49 \\
\hline Severe asthma & 14 & 13 & 19 & 23 \\
\hline \multicolumn{5}{|c|}{$\begin{array}{l}\text { *Index based on dispensed medications and medical services for asthma. } \\
\text { tIndex based on symptoms and forced expiratory volume in } 1 \mathrm{~s}\left(\mathrm{FEV}_{1}\right) \text {. } \\
\text { flndex based on symptoms and the current state of asthma management. } \\
\text { §Index based on reported daily medication use. }\end{array}$} \\
\hline
\end{tabular}

patients treated in asthma clinics were more likely to suffer from severe asthma, according to our criteria, than patients in the Québec cohort.

Our results also showed that the distribution of the level of asthma severity obtained by applying our database index to the Québec cohort was close to the distribution found with two of the three asthma severity indexes based on symptoms and pulmonary function that have been used in populations in France and the USA. ${ }^{2021}$ The distribution of severity found in the study conducted in Ontario was different from that found in the Québec cohort, which may be due to differences in the definition of severity. According to the Ontario index, patients were classified as having mild asthma if they used only bronchodilators to treat asthma and as having moderate or severe asthma when they were prescribed ICS while, in our index of severity, patients with a low dose of ICS could be classified as having mild asthma. Indeed, the other two indexes resemble ours more closely than the Ontario index.

This study has some limitations. First, with our database indexes it was sometimes difficult to distinguish precisely the difference between asthma severity and control since the markers of exacerbations and use of rescue medications were used in both definitions. The overlap in the definitions of asthma severity and control could also mean that the asthma was more uncontrolled in patients with severe asthma than in those with mild disease. This overlap could also have had an effect in the validation against $\mathrm{FEV}_{1}$ and $\mathrm{FEV}_{1} / \mathrm{FVC}$ measures in the asthma clinic population since these pulmonary function values may reflect both severity and control. However, the difficulty in making a clear distinction between asthma severity and control is not specific to our indexes and is also encountered in clinical practice. ${ }^{22}$ Second, our database index of severity was developed to measure disease severity in patients already treated for asthma and is based, at least in part, on the level of medication needed to attain control. ${ }^{3}$ Moreover, our indexes were validated in patients who were likely to be compliant with their treatment because they were under the care of respiratory specialists. However, with respect to general clinical practice, a proportion of patients will not attain control and this might reduce the capacity of our severity index to classify patients accurately. Third, our database index of control cannot detect short-term changes since it is based on medications and healthcare services dispensed over a 1 year period. A fourth limit of our study concerns the use of a single measure of lung function to validate the indexes. Use of only one measure of lung function might not be optimal for assessing a parameter that can fluctuate over time. Moreover, since the $\mathrm{FEV}_{1} / \mathrm{FVC}$ ratio was available only for a subset of patients from the clinics, we were not able to perform the agestratified analysis for this measure. Fifth, the patients included in the Québec cohort were not fully representative of the population since they did not include patients with private drug insurance plans and tended to over-represent patients of low to moderate socioeconomic status.
This study also has several strengths. The database indexes can assess asthma severity and control among patients already treated for asthma and are, at least in part, based on the use of acute care for asthma which is a well recognised marker of asthma severity and lack of control. ${ }^{3}$ Moreover, the data obtained from the Prescription Drug Insurance database regarding the mean dose of ICS and SABA are considered to be a good reflection of usual dosage. ${ }^{23-27}$ Our indexes were validated against pulmonary function measures that are well established measures of asthma severity and control. Moreover, the age-stratified analysis allowed us to assess the validity of our database index across different age groups. Finally, the distribution of asthma severity found with our database index when applied to the Québec cohort was found to be comparable to the distribution of severity assessed with other indexes applied to two of the three different population samples we used for comparison.

In conclusion, we have shown that the database indexes that we developed based on dispensed asthma medications and medical services are valid to the extent that we could test this and could adequately classify currently treated patients with asthma into categories of severity and control. In the absence of clinical data, our database indexes could be used in epidemiological studies using administrative databases reasonably to assess the severity and control of asthma among adult patients and thus improve the quality of database studies in the field of asthma. Further research will be needed to confirm these findings and to adapt and validate these database indexes for use in special populations including pregnant women, older people and children.

\section{ACKNOWLEDGEMENTS}

The authors thank Ms Brigitte Morin from the Régie de l'assurance maladie du Quebec (RAMQ) for her assistance with the data and $\mathrm{Mr}$ Hatch for the English revision of the manuscript.

\section{Authors' affiliations \\ Faranak Firoozi, Université de Montréal, Québec, Canada Catherine Lemière, Marie-France Beauchesne, Amélie Forget, Lucie Blais, Université de Montréal and Centre de Recherche de l'Hôpital du Sacré- Cœur de Montréal, Québec, Canada}

$L B$ and $C L$ are the recipients of a New Investigator Award for salary support from the Canadian Institutes for Health Research (CIHR); LB and M-FB hold the AstraZeneca Chair in Respiratory Health; and FF is the recipient of a Doctoral Training Award from the Fonds de la Recherche en Santé du Quebec (FRSQ).

Competing interests: None.

\section{REFERENCES}

1 National Asthma Education and Prevention Program. Guidelines for the diagnosis and management of asthma, Expert Panel Report 2.Publication No 974051, 1997.

2 Global Initiative for Asthma. Global strategy for asthma management and prevention, NIH Publication No 02-3659, 2002. 
3 Boulet LP, Becker A, Berube D, et al. Canadian asthma consensus report, 1999 Canadian Asthma Consensus Group. CMAJ 1999:161(11 Suppl):S1-61.

4 Blais L, Suissa S, Boivin JF, et al. First treatment with inhaled corticosteroids and the prevention of admissions to hospital for asthma. Thorax 1998;53:1025-9.

5 Blais L, Ernst P, Boivin JF, et al. Inhaled corticosteroids and the prevention of readmission to hospital for asthma. Am J Respir Crit Care Med 1998; 158:126-32

6 Eisner MD, Ackerson LM, Chi F, et al. Health-related quality of life and future health care utilization for asthma. Ann Allergy Asthma Immunol 2002;89:46-55.

7 Ungar WJ, Chapman KR, Santos MT. Assessment of a medication-based asthma index for population research. Am J Respir Crit Care Med 2002;165:190-4.

8 Atta JA, Nunes MPT, Fonseca-Guedes CHF, et al. Patient and physician evaluation of the severity of acute asthma exacerbations. Brazil J Med Biol Res 2004;37:1321-30.

9 Vollmer WM, Markson LE, O'Connor E, et al. Association of asthma control with health care utilization and quality of life. Am J Respir Crit Care Med 1999; 160:1647-52.

10 Lee S, Kirking DM, Erickson SR. Methods of measuring asthma severity and influence on patient assignment. Ann Allergy Asthma Immunol 2003;91:449-54.

11 Juniper EF, O'Byrne PM, Guyatt GH, et al. Development and validation of a questionnaire to measure asthma control. Eur Respir J 1999;14:902-7.

12 Nathan RA, Sorkness CA, Kosinski M, et al. Development of the asthma control test: a survey for assessing asthma control. J Allergy Clin Immunol 2004; 113:59-65

13 Régie de l'assurance maladie du Québec. Statistiques annuelles. Québec: Régie de l'assurance maladie du Québec, 1997.

14 Tamblyn $\mathbf{R}$, Lavoie $G$, Petrella $L$, et al. The use of prescription claims databases in pharmacoepidemiological research: the accuracy and comprehensiveness of the prescription claims database in Québec. J Clin Epidemiol 1995;48:999-1009.

15 Blais L, Lemière C, Berbiche D. Validation of asthma diagnostic codes in the administrative health databases of Québec, Canada. Pharmacoepidemiol Drug Saf 2004;13:S32.
16 Cockcroft DW, Swystun VA. Asthma control versus asthma severity. J Allergy Clin Immunol 1996:98:1016-8.

17 Blais L, Beauchesne MF. Use of inhaled corticosteroids following discharge from an emergency department for an acute exacerbation of asthma. Thorax 2004:59:943-7.

18 Martel MJ, Rey É, Beauchesne M-F, et al. Use of inhaled corticosteroids during pregnancy and risk of pregnancy induced hypertension: nested case-control study. BMJ 2005;330:230-3.

19 Blais L, Beauchesne M-F, Lévesque S. Socio-economic status and medication patterns in pediatric asthma in Canada. J Adolesc Health 2006;38:607.

20 Liard R, Leynaert B, Zureik M, et al. Using Global Initiative for Asthma guidelines to assess asthma severity in populations. Eur Respir J 2000;16:615-20.

21 Rabe KF, Adachi M, Lai CK, et al. Worldwide severity and control of asthma in children and adults: the global asthma insights and reality surveys. J Allergy Clin Immunol 2004;114:40-7.

22 Fuhlbrigge AL. Asthma severity and asthma control: symptoms, pulmonary function, and inflammatory markers. Curr Opin Pulm Med 2004;10:1-6.

23 Cochrane MG, Bala MV, Downs KE, et al. Inhaled corticosteroids for asthma therapy: patient compliance, devices, and inhalation technique. Chest 2000; 1 17:542-50

24 Paganini-Hill A, Ross RK. Reliability of recall of drug usage and other healthrelated information. Am J Epidemiol 1982;116:114-22.

25 Van den Brandt PA, Petri H, Dorant E, et al. Comparison of questionnaire information and pharmacy data on drug use. Pharm Weekbl [Sci] $1991 ; 13: 91-6$.

26 West SL, Savitz DA, Koch G, et al. Recall accuracy for prescription medications: self-report compared with database information. Am J Epidemiol 1995;142:1103-12.

27 Metlay JP, Hardy C, Strom BL. Agreement between-patient self-report and a Veterans Affairs national pharmacy database for identifying recent exposures to antibiotics. Pharmacoepidemiol Drug Saf 2003;12:9-15.

\section{LUNG ALERT}

Combination treatment may help patients with COPD, but does not improve mortality

$\Delta$ Calverley PM, Anderson JA, Celli B. Salmeterol and fluticasone propionate and survival in chronic obstructive disease. N Engl Med 2007;356:775-89.

T his multicentre, randomised, double blind trial comparing the combination of salmeterol and fluticasone propionate $50 / 500 \mu \mathrm{g}$ twice daily with placebo, salmeterol alone or fluticasone alone was carried out over a period of 3 years. Subjects included current or ex-smokers with at least a 10-pack year history, a diagnosis of chronic obstructive pulmonary disease (COPD) and a prebronchodilator forced expiratory volume in $1 \mathrm{~s}\left(\mathrm{FEV}_{1}\right)$ of less than $60 \%$ predicted. There were four treatment groups into which the 6184 patients were randomised.

All-cause mortality rates (the primary outcome) were $12.6 \%$ in the combination group, $15.2 \%$ in the placebo group, $13.5 \%$ in the salmeterol group and $16.0 \%$ in the fluticasone group. The absolute risk reduction for death in the combination treatment group compared with the placebo group was $2.6 \%$ but this did not reach statistical significance $(p=0.052)$.

There was an increased incidence of pneumonia in the fluticasone propionate treatment regimes $119.6 \%$ in the combination group, $18.3 \%$ in the fluticasone group, $13.3 \%$ in the salmeterol group and $12.3 \%$ in the placebo group; $\mathrm{p}<0.001$ for comparison between both combination treatment and fluticasone groups and the placebo group) but this did not translate to an increase in the number of deaths.

The high dropout rate in the placebo group may well have led to a loss of sensitivity of the data as these patients may then have gone on to active treatment, making it more difficult to detect superiority of the active treatment arm.

The TORCH study provides us with important data on the natural progression of COPD. However, although the salmeterol-fluticasone combination failed to demonstrate an improvement in mortality according to the predefined statistical criteria, it did show significant improvements in exacerbation rates, health status and lung function.

Sundari Ampikaipakan

Specialist Registrar in Respiratory Medicine, Norfolk and Norwich University Hospital; sundari.ampi@nnuh.nhs.uk 